\title{
Origin of the complex karyotype of the polyploid parthenogenetic grasshopper Saga pedo (Orthoptera: Tettigoniidae)
}

\author{
AnNe Marie DUTRILlaUX ${ }^{1}$, Michèle LEMONNIER-DARCEMONT², Christian DARCEMONT², \\ Vladimir KRPAČ ${ }^{3}$, Pierre FOUCHET ${ }^{4}$ and Bernard DUTRILLAUX ${ }^{*}$ \\ ${ }^{1}$ Muséum National d'Histoire Naturelle, UMR 7205-OSEB, CNRS/MNHN, 16, rue Buffon, CP 39, 75005 Paris, France; \\ e-mail: bdutrill@mnhn.fr \\ ${ }^{2}$ Groupement d'Etudes Entomologiques Méditerranée (G.E.E.M.), Hameau de Saint Donat, 240 chemin du Vignaou, 83440 Callian, \\ France; e-mail: etude.saga@geem.org \\ ${ }^{3}$ National Institution Macedonian Museum of Natural History, Boulevard Ilinden 86, Skopje - 1000, Republic of Macedonia; \\ e-mail: vkrpach@gmail.com \\ ${ }^{4}$ Laboratoire Gamétogenèse, Apoptose et Génotoxicité, INSERM U566, Institut de Radiobiologie Cellulaire et Moléculaire, \\ Direction des Sciences du Vivant, CEA, 92265 Fontenay aux Roses, France; e-mail: pierre.fouchet@cea.fr
}

Key words. Tettigoniidae, Saga pedo, chromosomes, DNA content, karyotype evolution, pentaploidy

\begin{abstract}
Karyotypes of the polyploid parthenogenetic species Saga pedo from four localities in France and the Republic of Macedonia were constructed and compared. All these karyotypes consist of 70 chromosomes, which is more than twice that in other species of the genus. The chromosomes differ from each other, making the matching of homologues difficult. Karyotypes of French specimens are similar, except for differences in the heterochromatin. Compared to that of the Macedonian specimens those from French specimens differ by the shortening of a single chromosome. The difficulty experienced in identifying tetrads and even pairs of chromosomes indicates that either many chromosome rearrangements have occurred since the polyploidisation event(s) or that the addition of quite different genomes is the cause. On the other hand, that the karyotypes are similar indicates a common origin of both the Macedonian and French populations. Thus, most chromosome changes preceded the separation from their common ancestor. Both the DNA content and chromosome analyses suggest that the $S$. pedo karyotype is pentaploid and not tetraploid as previously proposed. This odd ploidy number rules out the hypothesis that it could only have originated by endoreduplication. It is more likely that it originated by the association of five copies of the 14,X haploid karyotype, which exists in the gametes of the closely related species, $S$. campbelli and $S$. rammei (male / female $2 \mathrm{n}=27, \mathrm{X} / 28, \mathrm{XX}$ ). Fertilization of a parthenogenetic 56, XXXX female by a $14, \mathrm{X}$ spermatozoa could have resulted in the last increase in ploidy.
\end{abstract}

\section{INTRODUCTION}

Saga pedo Pallas 1771, one of two parthenogenetic grasshoppers (Hewitt, 1979), belongs to a small genus that occurs in the Paleartic region. There are seven species in Europe. All but $S$. pedo occur only in the Balkans and neighbouring countries. S. pedo has a wider distribution, reaching Spain, through Italia, Switzerland, and France to the West and China through Russia to the East. It was accidentally transported by man to the USA, where it is recorded from Michigan (Cantrall, 1972). This colonisation success may be attributed to the ability of females to produce females without fertilization (thelytoky). Thus a single female can colonize an empty niche (Mittwoch, 1978), but this colonisation success is limited: $S$. pedo remains rare and occurs in scattered localities. Since Matthey (1946) it has been assumed that $S$. pedo is tetraploid. In animals, most parthenogenetic species have polyploid karyotypes, whose origin and causality relationships with parthenogenesis remain a matter of debate. Several routes may lead to polyploidy, which may be either the cause or the consequence of parthenogenesis (Mittwoch, 1978). We have recently studied the karyo- type of $S$. pedo from one locality in France and found it consisted of 70 chromosomes, which is more than twice the number observed in other species of Saga (Lemonnier-Darcemont et al., 2008; Warchalowska-Sliva et al., 2007, 2009). Furthermore, when establishing its karyotype, it was difficult to identify quadruplets and even pairs of large chromosomes. This may have two non-exclusive explanations: either this karyotype was formed by the juxtaposition of several different genomes by successive hybridizations, or it has become unstable, following polyploidization by endoreduplication. Recent molecular studies on Coleoptera have revealed the complexity of the problem. It appears that, in a given species, both parthenogenesis and polyploidization can occur repeatedly and independently (Gómez-Zurita et al., 2006). As concluded by White \& Contreras (1981), after an extensive study of the other parthenogenetic grasshopper Warramaba virgo "it is unlikely that the above questions can be answered in any simple universally valid manner". In this work, we initially tried to answer an apparently simple question by comparing the karyotypes of specimens of $S$. pedo from distant regions: are their chromo-

\footnotetext{
* Corresponding author.
} 

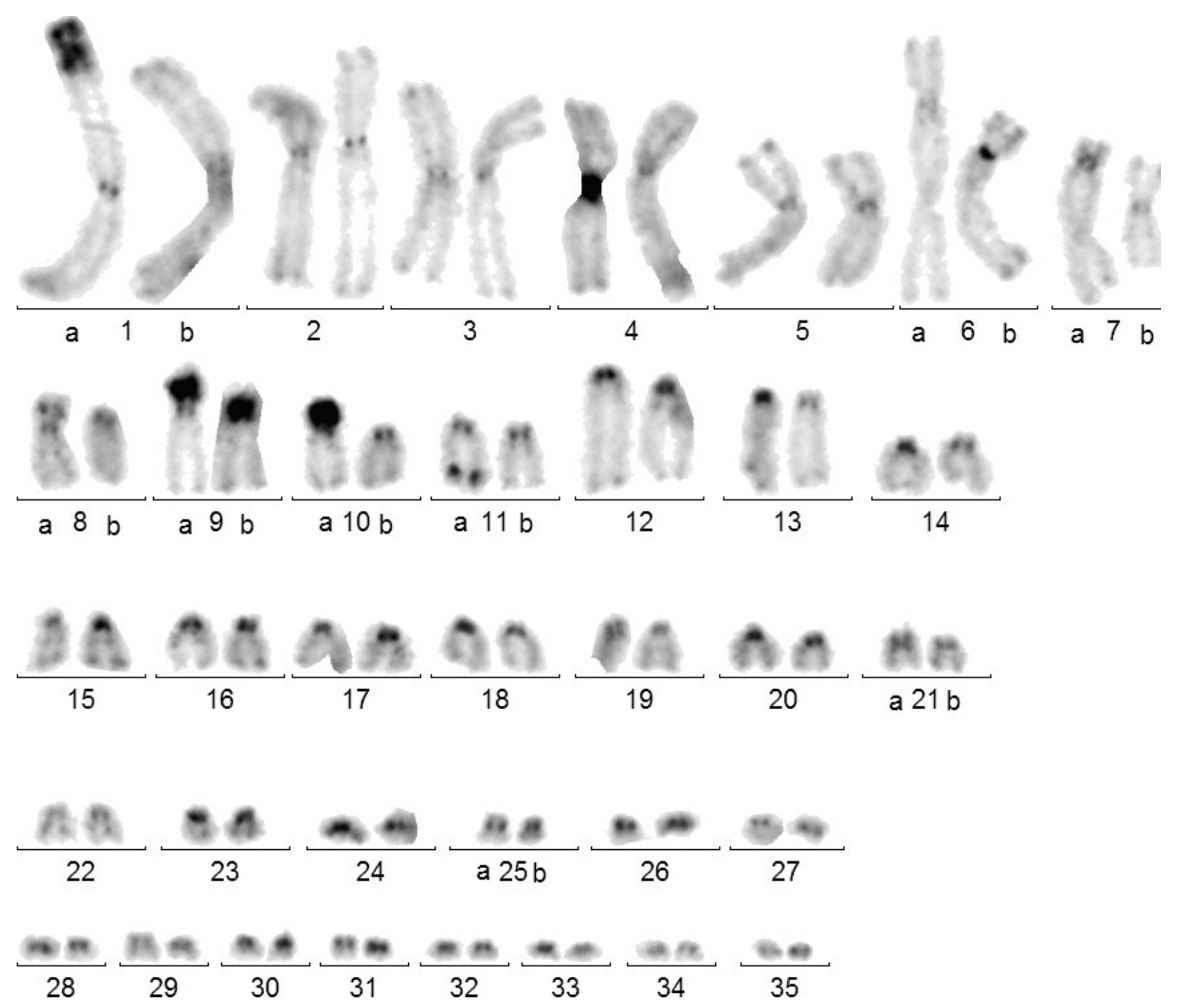

Fig. 1. C-banded karyotype of Saga pedo (specimen 2) from the Alpes Maritimes (France).

somes similar, which would suggest a unique origin and genomic stability, or very different, suggesting either multiple origins of the polyploidy or marked chromosomal instability or both? Finally, a comparison with other European species of Saga indicates that the karyotype of $S$. pedo is pentaploid and may derive from that of closely related species with $27-28$ chromosomes.

\section{MATERIAL AND METHODS}

\section{Animals}

S. pedo is a protected species in Europe, and we obtained authorization to collect specimens in France and the Republic of Macedonia. The specimens studied originated from the following four locations:

- specimens 1 and 2: offspring reared in the laboratory of females captured near Coursegoules, Alpes Maritimes, France $\left(007^{\circ} 02^{\prime} \mathrm{E} / 43^{\circ} 45^{\prime} \mathrm{N}\right)$;

- specimen 3: juvenile female captured near Les Mayons, Var, France $\left(006^{\circ} 21^{\prime} \mathrm{E} / 43^{\circ} / 17^{\prime} \mathrm{N}\right)$;

- specimen 4: female captured near Fos-sur-mer, Bouches du Rhône $\left(004^{\circ} 56^{\prime} \mathrm{E} / 43^{\circ} 28^{\prime} \mathrm{N}\right)$;
- specimens 5 and 6: juvenile females captured near Ohrid, Republic of Macedonia $\left(20^{\circ} 50^{\prime} \mathrm{E} / 40^{\circ} 58^{\prime} \mathrm{N}\right)$.

For each specimen, 5 to 15 metaphases were photographed and 2 to five karyotypes established using an IKAROS (MetaSystems, Altlussheim, Germany) device.

\section{Cell suspension}

This study was done at the MNHN laboratory (Paris, France) except for the dissection and slide preparation of specimen 5, which was done in the laboratory of Zissis Mamuris (Larissa, Greece). A few hours after feeding and 3 hours after intraabdominal injection of colcemide, the animals were anaesthetised with ethyl acetate and decapitated. The ventral cuticle was cut longitudinally and the gut removed. The body was dipped in a $0.88 \mathrm{~g} / 1 \mathrm{KCl}$ aqueous solution, and the internal part of the dorsal part scratched with mounted needles. The resultant cell suspension, which consisted of a mixture of stromal and neural cells, was sucked up into a pipette and the operation repeated several times. This cell suspension was used for cytogenetic and flow cytometry analyses. Tissue fragments were frozen for further molecular studies. Cell suspensions from $S$. rammei Kaltenbach, 1965 and $S$. campbelli Uvanov, 1921 reported in Lemonnier-Darcemont et al. (2008) were used for flow 

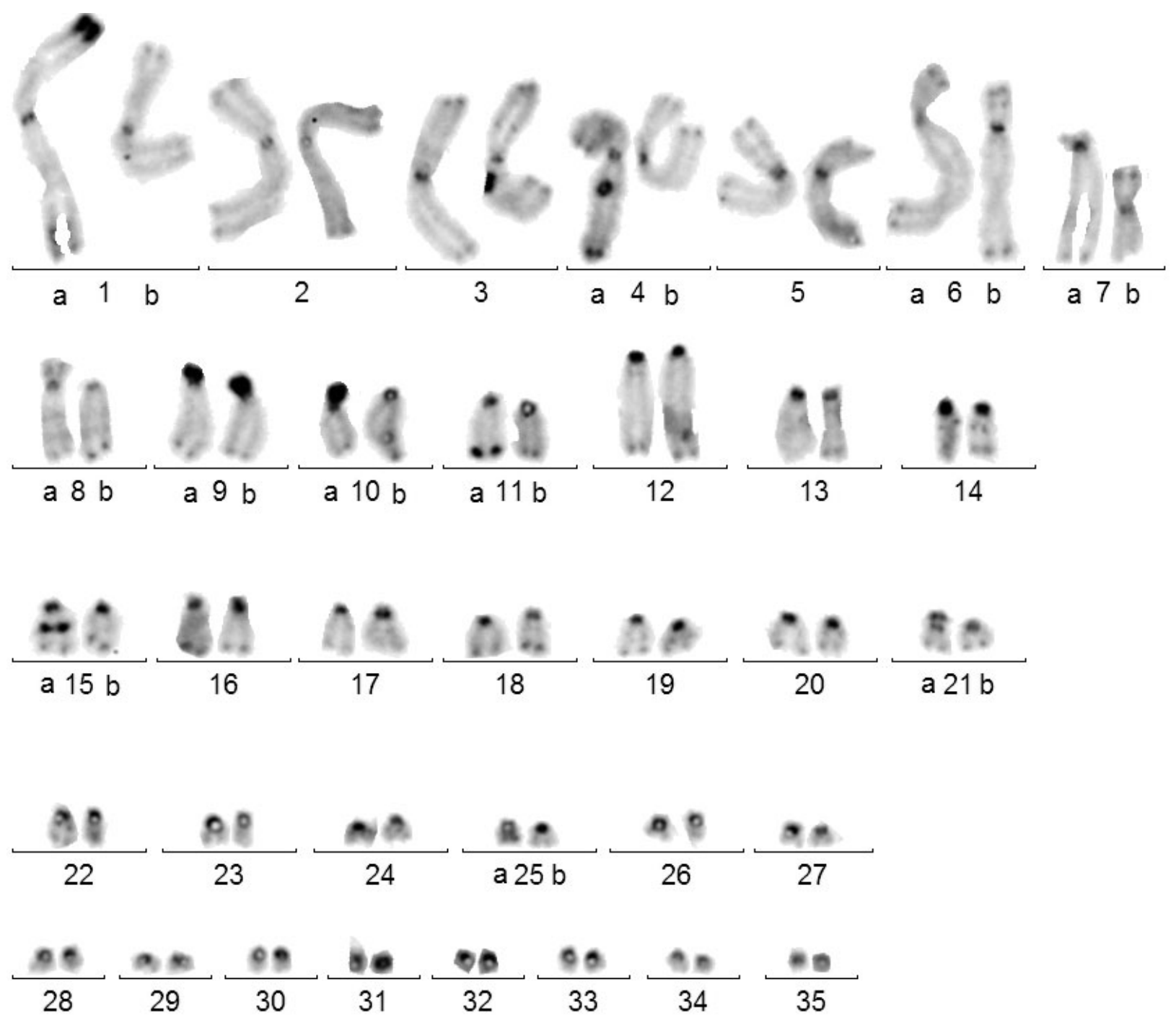

Fig. 2. C-banded karyotype of Saga pedo (specimen 4) from Bouches-du-Rhone (France).

cytometry (see below), as well as control cells from laboratory mouse (Mus musculus).

\section{Cytogenetics}

After centrifugation and elimination of the supernatant, the cell pellets were suspended in hypotonic solution: either calf serum diluted in water ( 1 vol. : 2 vol.) or $0.55 \mathrm{~g} / 1 \mathrm{KCl}$ aqueous solution. After 15-20 min, the hypotonic solutions were replaced by Carnoy's fixative. The slide preparation, chromosome staining and C-, Q-, and DAPI-banding were performed as described by Dutrillaux \& Couturier (1981) and Dutrillaux et al. (2006, 2007). Briefly, after one change of fixative, drops of the cell suspension were placed on cool wet slides, left to dry, and kept at $-20^{\circ} \mathrm{C}$ until used. In order to reduce background staining the slides were treated for $45 \mathrm{~min}$ in $2 \times \mathrm{SSC}$ at $60^{\circ} \mathrm{C}$ before staining with fluorochromes or Giemsa (4 min in $2 \%$ Giemsa). Metaphases were photographed before treatment for C-banding: 50 min in $2 \mathrm{~N} \mathrm{HCl}$ at room temperature, 5 min in $0.3 \mathrm{~N} \mathrm{Ba}(\mathrm{OH})$ at $30^{\circ} \mathrm{C}, 50 \mathrm{~min}$ in $2 \times \mathrm{SSC}$ at $60^{\circ} \mathrm{C}$, and $10 \mathrm{~min}$ in $2 \%$ Giemsa.

\section{Nomenclature}

There is no officially established cytogenetic nomenclature for insects. Therefore, we followed, as closely as possible the International System for Chromosome Nomenclature (ISCN,
Mittelman, 1995), generally used for mammalian chromosomes. We used the following definitions and abbreviations:

- acrocentric: any chromosome with a unique euchromatic arm, whatever the size of its purely heterochomatic (C-banded) other arm (Fig. 1, chromosomes 9-12, among others);

- metacentric: any chromosome with a centromeric index (euchromatic short arm/total euchromatin length ratio) within the range of $0.40-0.50$ (Fig. 1, chromosomes 1-5);

- sub-metacentric: all others (Fig. 1, chromosomes 6-8a).

\section{Flow cytometry}

Cells in suspension in $3 \mathrm{ml}$ of $0.88 \mathrm{~g} / 1 \mathrm{KCl}$ aqueous solution were dissociated using a vortex while drops of absolute ethanol were added to obtain a final volume of $10 \mathrm{ml}$. This cell suspension was stored at $4^{\circ} \mathrm{C}$. Cells were washed in PBS, and finally stained for $1 \mathrm{~h}$ in PBS supplemented with propidium iodide (40 $\mu \mathrm{g} / \mathrm{ml})$ and RNAase $(100 \mu \mathrm{g} / \mathrm{ml})$. Flow analysis was performed using a FACSCalibur (Becton Dickinson, Franklin Lakes, NJ, USA).

\section{RESULTS}

\section{Karyotyping}

In this presumed tetraploid karyotype (Matthey, 1946; Hewitt, 1979), it was often impossible to identify quadru- 

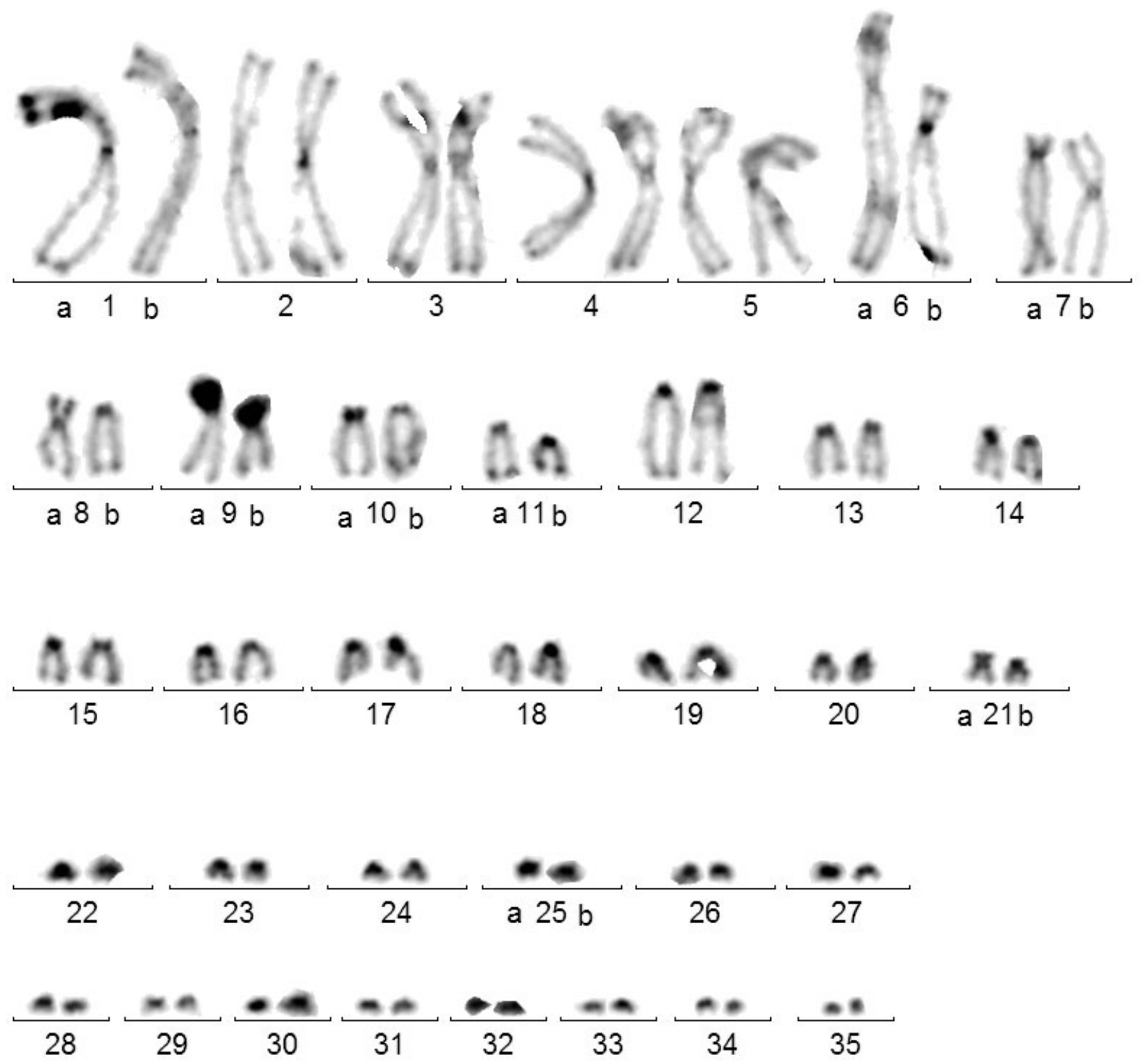

Fig. 3. C-banded karyotype of Saga pedo (specimen 6) from Orhid - Galièica (Macedonia).

plets, and even pairs. Thus, chromosomes of roughly similar length and morphology were arbitrarily paired, without presumption of their homology. We adopted this non-conventional classification in order to facilitate interindividual comparisons. In some "pairs", we called a and $\mathrm{b}$ the chromosomes which were obviously different. All the karyotypes were composed of 70 chromosomes. The presence of unique copies of many chromosomes demonstrates that the analysed metaphases represent the constitutional karyotype and not that of polyploid tissue.

\section{C-banding}

(1) Specimens $\mathrm{N}^{\circ} 1$ and 2. Ten chromosomes $\left(\mathrm{N}^{\circ} 1-5\right)$ are metacentric and five submetacentric $\left(\mathrm{N}^{\circ} 6,7\right.$, and $\left.8 \mathrm{a}\right)$. One (specimen 1, Lemonnier-Darcemont et al., 2008) or three acrocentrics $\left(\mathrm{N}^{\circ} 9 \mathrm{a}\right.$ and $\mathrm{b}$ and 10a, Fig. 1) have a large heterochromatic short arm. All the others but for two small metacentric chromosomes $\left(\mathrm{N}^{\circ} 21 \mathrm{a}\right.$ and $\left.25 \mathrm{a}\right)$ are acrocentric, of progressively decreasing sizes. Centro- meric regions of acrocentrics are often more intensely C-banded than those of other chromosomes, probably because the heterochromatic short arm was indistinctly stained by Giemsa. In a distal position on one large metacentric $\left(\mathrm{N}^{\circ}\right.$ 1a) and one acrocentric $\left(\mathrm{N}^{\circ}\right.$ 11a) there is a large heterochromatic segment, and most telomeric regions of chromosomes 1 to 22 are discretely C-banded. Discrete intercalary C-bands are occasionally observed on some small acrocentric chromosomes, such as $\mathrm{N}^{\circ} 14,15$, and 17.

Finally, the karyotypes of specimens 1 (not shown) and 2 (Fig. 1) differ in the amount of heterochromatin in the short arms of chromosome 9 and 10.

(2) Specimen $\mathrm{N}^{\circ} 3$. Its karyotype (not shown) is very similar to those described above, except that four acrocentrics have short arms $\left(\mathrm{N}^{\circ} 9 \mathrm{a}, \mathrm{b}\right.$ and $\left.10 \mathrm{a}, \mathrm{b}\right)$ with a large heterochromatic segment. The different amounts of euchromatin indicate that they are not homologous. 


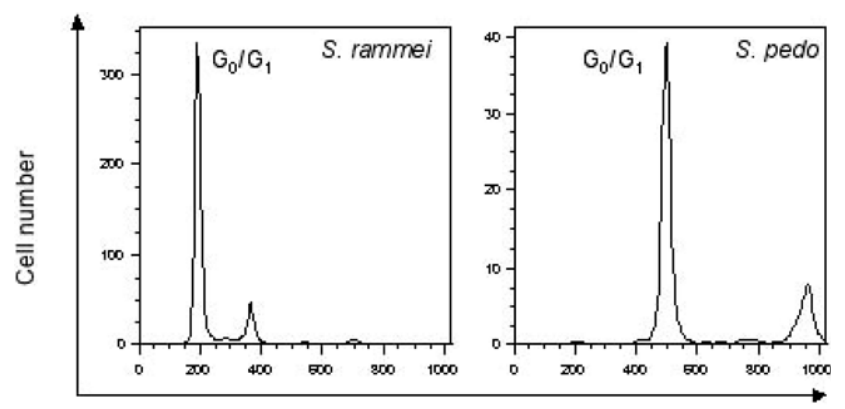

DNA content - Propidium iodide fluorescence

Fig. 4. DNA content of Saga rammei and Saga pedo measured using flow cytometry.

(3) Specimen $\mathrm{N}^{\circ} 4$ (Fig. 2). Its karyotype has the same euchromatic characteristics as above. Three acrocentrics $\left(\mathrm{N}^{\circ} 9 \mathrm{a}, \mathrm{b}\right.$ and 10a) have a large heterochromatic short arm and telomeric $\mathrm{C}$-banding on some chromosomes, $\mathrm{N}^{\circ} 4 \mathrm{a}$ in particular, is more intense than in specimens 1-3. Finally, one acrocentric $\left(\mathrm{N}^{\circ} 15 \mathrm{a}\right)$ carries an intense $\mathrm{C}$-band in an intercalary position, not seen in other specimens.

(4) Specimens $\mathrm{N}^{\circ} 5$ and 6. Both karyotypes comprise 15 metacentrics or submetacentrics (Fig. 3 of specimen $\mathrm{N}^{\circ} 6$ ), as in the specimens from France and the heterochromatic components on chromosomes 1, 9, 10, and 11 exhibit the same characters. The relative sizes and morphologies of the chromosomes are also comparable, with one noticeable exception. Chromosome $7 \mathrm{~b}$, which is much smaller than chromosomes 5 and $7 \mathrm{a}$ in French specimens, is of similar size in these specimens. This suggests that, beside the polymorphism of the heterochromatin, the karyotypes of specimens from France and Macedonia differ by one structural rearrangement, at least.

\section{Q- and DAPI-banding}

The staining by quinacrine mustard, performed on an additional specimen $\left(\mathrm{N}^{\circ} 7\right)$ from Macedonia, gave a reverse C-banding, i.e., fairly bright euchromatin and dull heterochromatin (not shown). The staining with DAPI was similar to that obtained with quinacrine, but in some metaphases, a very small spot of fluorescence was observed at the centromere location (not shown). Since these fluorochromes are expected to stain preferentially A-T rich DNA, the results indicate that most heterochomatin is not A-T rich, except at centromere location. In this study no banding of euchromatin was observed.

\section{Heterochromatin variation and stability}

The global heterochromatin pattern is surprisingly similar in specimens from the different localities studied: the only recurrent variation affects the amount of heterochromatin in the short arms of a few acrocentrics. Unlike in bisexual species, it is worth noting that heterochromatin is not located on obviously homologous chromosomes. In the different specimens, telomeric C-bands are present on the same chromosomes, but their size and intensity can vary. C-bands located around centromeric regions are very well conserved. For instance, considering the submetacentric chromosomes, easy to identify
$\mathrm{C}$-bands are faint on $6 \mathrm{a}$, intense on $6 \mathrm{~b}$, large and diffuse on $7 \mathrm{a}$ and faint on $7 \mathrm{~b}$. This pattern is consistent in the specimens from the four localities, even for chromosome $7 \mathrm{~b}$ that has been modified by translocation or deletion, which suggests they have a common origin.

\section{DNA content}

The DNA content was measured by flow cytometry in one specimen of the following species: Saga campbelli, Saga rammei, and Saga pedo. The S. pedo/S. rammei DNA content ratio was 2.6 in two independent experiments (Fig. 4). As expected, this ratio is very close to that of the chromosome numbers of these two species: 70/28 and $70 / 27=2.59$ and 2.5 for females and males, respectively. It indicates that the increased number of chromosomes in $S$. pedo is a consequence of polyploidization and not the fission of chromosomes. In order to quantify the DNA content of the cells of $S$. campbelli, S. rammei, and mouse (Mus musculus) were analysed. Those of $S$. rammei and $S$. campbelli had exactly the same DNA content, which was 1.16 times that of mouse $(3.30 \mathrm{pg}$ per $1 \mathrm{C}$ DNA; Gregory, 2008). Thus, S. campbelli and S. rammei DNA content is about $3.83 \mathrm{pg}$ and that of $S$. pedo, 10.06 pg per 1C DNA.

\section{DISCUSSION}

Among insects, the karyotype of Saga pedo is certainly one of the most difficult to establish because its 70 chromosomes often cannot be paired. Matthey (1941, 1946) reports there is no meiosis and based on counts of 68 chromosomes for specimens from Switzerland, proposes the species is tetraploid. The difference between 68 and 70 may be the consequence of technical limitations in the 1940's, rather than geographical variation, but more specimens from Switzerland need to be studied. In spite of these difficulties, it was possible to compare the chromosomes of the specimens from different localities. The shortest distance between the French and Macedonian localities is about $2,000 \mathrm{~km}$. From field studies, it was estimated that the maximum average distance travelled by these wingless insects during their life may reach $500 \mathrm{~m}$, and breeding experiments have shown that it takes them 3 years to complete a generation (Lemonnier-Darcemont et al., in press). Thus, specimens from the Republic of Macedonia and France are separated from their last common ancestors by a minimum of 4,000 generations or 12,000 years. Indeed, this is likely to be an underestimate, as Matthey (1941) placed the origin of $S$. pedo in the Pliocene (2-5 million years ago). Specimens from the same location have the same karyotype, except for the variation in the heterochromatin in the short arms of acrocentric chromosomes. Such variation is common in bisexual species but can occur among the clones produced by parthenogenetic species. In the absence of meiosis (Matthey, 1941), it must principally be the consequence of mitotic exchanges between acrocentric short arms, in either germ or early zygotic cells. In bisexual species, heterochromatin is usually located on both homologues, which is assumed to be the consequence of their meiotic recombination. In $S$. pedo, the absence of meiosis and thus also of 
TABle 1. Karyotype formulae of European diploid non-parthenogenetic Saga species and their haploid gametes (from Matthey, 1946; Goldschmidt, 1946; Warchalowska-Sliva et al., 2007; Lemonnier-Darcemont et al., 2008). X, X chromosome; m, metacentric autosome.

\begin{tabular}{|c|c|c|c|c|c|}
\hline & Females & Oocytes & Males & \multicolumn{2}{|c|}{ Spermatozoa } \\
\hline $\begin{array}{l}\text { S. ornata } \\
\text { S. cappadocica }\end{array}$ & $32, \mathrm{XX}$ & $16, X$ & $31, X$ & $16, X$ & 15 \\
\hline $\begin{array}{l}\text { S. natoliae } \\
\text { S. helenica } \\
\text { S. rhodiensis }\end{array}$ & $30, \mathrm{XX}, \mathrm{m}, \mathrm{m}$ & $15, \mathrm{X}, \mathrm{m}$ & $29, \mathrm{X}, \mathrm{m}, \mathrm{m}$ & $15, \mathrm{X}, \mathrm{m}$ & $14, \mathrm{~m}$ \\
\hline $\begin{array}{l}\text { S. campbelli } \\
\text { S. rammei }\end{array}$ & $28, \mathrm{XX}, \mathrm{m}, \mathrm{m}, \mathrm{m}, \mathrm{m}$ & $14, \mathrm{X}, \mathrm{m}, \mathrm{m}$ & $27, \mathrm{X}, \mathrm{m}, \mathrm{m}, \mathrm{m}, \mathrm{m}$ & $14, \mathrm{X}, \mathrm{m}, \mathrm{m}$ & $13, \mathrm{~m}, \mathrm{~m}$ \\
\hline
\end{tabular}

meiotic recombination, may explain why large amounts of heterochromatin are not located in apparently homologous chromosomes. The specimens from the three French localities have similar karyotypes (except for the distribution of heterochromatin). They are surprisingly similar to those from Macedonia. However, the difference in the size of one sub-metacentric chromosome is interesting and might be useful in tracking their chromosomal evolution, which will be considered below.

There are two main hypotheses for explaining the formation of polyploid karyotypes, most frequently observed in parthenogenetic insects. The first and simplest is the doubling of the original diploid chromosome set by endoreduplication. This forms chromosome quadruplets, but it is unknown whether chromosome rearrangements can accumulate and alter the quadruplets. In the thelytokous $S$. pedo, the absence of meiosis means there is no gametic barrier against balanced structural rearrangements, unlike in bisexual species. Thus, there is no constraint to the emergence of descendents with new karyotypes. The presence of several unique copies of submetatric chromosomes $\left(\mathrm{N}^{\circ} 6 \mathrm{a}\right.$ and $\mathrm{b}, 7 \mathrm{a}$ and $\mathrm{b}$, and $\left.8 \mathrm{a}\right)$ may support such a scenario. The second hypothesis proposes that several "hybridization" events can generate the polyploid karyotypes of parthenogenetic species (Takenouchi et al., 1986), which was demonstrated for a curculionid beetle using molecular analyses (Tomiuk \& Loeschke, 1992). Unfortunately, in these studies, only the number of chromosomes was counted.

A comparison of the chromosomes of $S$. pedo with those of closely related species may indicate which of the two scenarios is most likely. In the Balkans and neighbouring regions, which may be the geographical origin of $S$. pedo, there are six other species. All have a metacentric $\mathrm{X}$, which is the largest chromosome in their karyotypes (Warchalowska-Sliva et al., 2007; Lemonnier-Darcemont et al., 2008). Chromosomes 1, 2, and 6a of S. pedo may thus correspond to the Xs, more or less modified by inversions and, in the case of chromosome 1a, by gain of heterochromatin in the distal region. Two species $(S$. natoliae and $S$. helenica) possess one pair, and two others (S. campbelli and S. rammei), two pairs of large almost metacentric autosomes (Lemonnier-Darcemont et al., 2008). Thus, the karyotype of $S$. pedo, with 10-11 metacentric chromosomes could be derived from that of species like $S$. campbelli or $S$. rammei, which could form 12 metacentrics by endoreduplication, but the origin of the
4-5 submetacentrics $\left(\mathrm{N}^{\circ} 6,7\right.$, and 8a) of $S$. pedo would remain a mystery. They could originate by translocations of acrocentrics or be derived from chromosomes of the ancestral species with more non-acrocentric autosomes. However, this does not fit with the high number of acrocentrics in $S$. pedo.

The comparison of the specimens from France and Macedonia is interesting. In Macedonia, the presence of 11 large metacentrics can be interpreted as the conservation of one more ancestral chromosome than in France, after polyploidization of a karyotype with six metacentric chromosomes. One additional rearrangement would have occurred in specimens from France. Interestingly, the submetacentric chromosomes $\left(\mathrm{N}^{\circ} 6,7 \mathrm{a}\right.$, and $\left.8 \mathrm{a}\right)$ are unique, but similar in French and Macedonian karyotypes. This indicates they were formed after the polyploidization event, either by endoreduplication or hybridizations, but before the French and Macedonian ancestors separated.

That either hybridization or endoreduplication occurred can be envisaged based on chromosome numbers. The formation of the karyotype of $S$. pedo with 70 chromosomes, comprising 15 metacentric/submetacentric chromosomes is difficult to reconstruct. The similarity of the karyotypes of two populations that separated a long time ago, suggests that the chromosome structure is very stable. This karyotype cannot be derived, without chromosome losses or gains, by duplicating an XX diploid female karyotype, which would give multiples of four, such as 68 or $72, \mathrm{XXXX}$. It might originate by gametic combinations from ancestral species and, therefore, it is informative to consider other species of Saga living in the Balkans and neighbouring regions. Their karyotypes are diploid and have undergone a simple evolution involving Robertsonian fusions between acrocentric chromosomes, resulting in an increase in the number of meta-/submetacentric chromosomes from two to six and decrease in the total number of chromosomes from $31-32$ to $27-28$ (Lemonnier-Darcemont et al., 2008, Table 1). Considering the outcome of all the theoretical gametic crosses, it appears that the 70 chromosomes, including 15 meta-/submetacentrics (Xs included) of $S$. pedo could be formed by a unique combination: a female tetraploid 56 , XXXX karyotype with 8 autosomal meta-/submetacentrics (four fold 14, X, each with 2 autosomal meta-/submetacentrics) + a male $14, \mathrm{X}$ haploid chromosome set, 
with 2 meta-/submetacentrics $=70, \mathrm{XXXXX}$, with 10 autosomal meta-/submetacentrics.

This combination is the only one that preserves the relative numbers of centromeres and euchromatic chromosome arms, and the chromosome balance. Consequently, the karyotype of $S$. pedo is not tetraploid, as previously proposed, but pentaploid, and resulted from the fertilization of a tetraploid oocyte from a species with a karyotype close to that of $S$. campbelli or $S$. rammei by a haploid spermatozoon. This fits with DNA content, which indicates that the genome of $S$. pedo is about 2.6 times that of $S$. rammei. Indeed, the observation of mating between $S$. pedo and S. rammei (Lemonnier-Darcemont \& Darcemont, 2007), suggests they are not so distantly related. This odd ploidy number recalls the situation in parthenogenetic beetles of the family Curculionidae, in which $3 \mathrm{n}$ and $5 \mathrm{n}$ ploidy are described, with molecular data favouring repeated additions of genomes (Tomiuk $\&$ Loeschcke, 1992). Multiple hybridizations have also occurred in the Australian parthenogenetic grasshopper Warramaba virgo, in which there are clones with different karyotypes, but which has remained diploid (White et al., 1977; White \& Contreras, 1981). The parthenogenesis of $S$. pedo may have been similarly initiated by juxtaposing different haploid genomes, but is more advanced in its evolution, as suggested by its more complex karyotype and wide geographical distribution. It may also be a consequence of polyploidy, which impedes meiotic cell divisions.

ACKNOWLEDGMENTS. We would like to thank Z. Mamuris, who allowed us to carry out some of the cytogenetic procedures in his laboratory in Larissa (Greece), and A. Segarra and J. Uhres from the French embassy in Skopje for their help in getting permission to collect Saga pedo.

\section{REFERENCES}

CAnTrall I.J. 1972: Saga pedo (Pallas) (Tettigoniidae: Saginae), an old word katydid new to Michigan. Gt Lake Entomol. 5: $103-106$.

Dutrillaux B. \& Couturier J. 1981: La Pratique de l'Analyse Chromosomique. Techniques de Laboratoire 12. Masson, Paris, pp. $1-87$.

Dutrillaux A.M., Moulin S. \& Dutrillaux B. 2006: Use of meiotic pachytene stage of spermatocytes for karyotypic studies in insects. Chromosome Res. 14: 549-557.

Dutrillaux A.M., Xie H. \& Dutrillaux B. 2007: Nucleolus and chromosome relationships at pachynema in four Scarabaeoidea (Coleoptera) species with various combinations of NOR and sex chromosomes. Chromosome Res. 15: 417-427.

GoldschmidT E. 1946: Polyploidy and parthenogenesis in the genus Saga. Nature 158: 587-588.

Gómez-Zurita J., FunK D.J. \& Vogler A.P. 2006: The evolution of the unisexuality in Calligrapha leaf beetles: molecular and ecological insights on multiple origins via interspecific hybridization. Evolution 60: 328-347.

Gregory T.R. 2008: Animal Genome Size Database. http://www.genomesize.com

Hewitt G. 1979: Animal Cytogenetics. Vol 3: Insecta 1. Orthoptera. Gebrüder Borntraeger, Berlin, Stuttgart, $170 \mathrm{pp}$.

ISCN 1995: International System for Human Chromosome Nomenclature 1995. Mittelman F. (ed.), S. Karger, Basel, 119 $\mathrm{pp}$.

Lemonnier-Darcemont M. \& Darcemont C. 2007: Hybridation entre Saga pedo (Pallas 1771) et Saga rammei Kaltenbach 1965 (Orthoptera: Tettigoniidae). Ann. Soc. Entomol. Fr. (n.s.) 43: 249-252.

Lemonnier-Darcemont M., Bernier C. \& Darcemont C. Statistical data on European Saga genus (Orthoptera: Tettigoniidae): Field and breeding data. Articulata 24(1) in press.

Lemonnier-Darcemont M., Dutrillaux A.M., Dutrillaux B. \& Darcemont C. 2008: Recherches sur la phylogénie de Saga pedo (Pallas, 1771) (Orthoptera: Tettigoniidae). Ann. Soc. Entomol. Fr. (n.s.) 44: 477-485.

Matthey R. 1941: Etude biologique et cytologique de Saga pedo Pallas. Rev. Suisse Zool. 48: 91-102.

MatTHEY R. 1946: Démonstration du caractère géographique de la parthénogenèse de Saga pedo Pallas et de sa polyploidie, par comparaison avec les espèces bisexuées $\mathrm{S}$. ephippigera Fisch. et S. gracilipes Uvar. Experientia 2: 260-261.

Mittelman F. (ed.) 1995: International System for Human Chromosome Nomenclature. S. Karger, Basel. pp. 1-119.

Мiтtwoсн U. 1978: Parthenegenesis. J. Med. Genet. 189: $165-181$.

Takenouchi Y., Suomalainen E., Saura A. \& Lokki J. 1986: Genetic polymorphism and evolution in parthenogenetic animals. XIII. Changes in the degree of polyploidy in Curculionidae. Japan. J. Genet. 61: 79-82.

Tomiuk J. \& LoeschCKe V. 1992: Evolution of parthenogenesis in the Otiorhynchus scaber. Heredity 68: 391-397.

WarchalowsKa-Sliva E., Maryanska-NadachowsKa A. \& Heller K.-G. 2007: Cytogenetic variability of the genus Saga Charp. (Orthoptera, Tettigoniidae, Saginae): heterochromatin differentiation. Caryologia 60: 29-36.

Warchalowska-Sliwa E., Grzywacz B., Maryanska-Nadachowska A., Karamysheva T.V., Rubtsov N.B. \& Chobanov D.P. 2009: Chromosomal differentiation among bisexual European species of Saga (Orthoptera: Tettigoniidae: Saginae) detected by both classical and molecular methods. Eur. J. Entomol. 106: 1-9.

White M.J.D. \& ContreRAs N. 1981: Chromosome architecture of the parthenogenetic grasshopper Warramaba virgo and its bisexual ancestors. In Bennet M.D., Bobrow M. \& Hewitt G. (eds): Chromosomes Today. Vol. 7. George Allen \& Unwin., London, pp. 165-175.

White M.J.D., Contreras N., Cheney J. \& Webb G.C. 1977: Cytogenetics of the parthenogenetic grasshopper Warramaba (formerly Moraba) virgo and its bisexual relatives.II. Hybridization studies. Chromosoma 61: 127-148.

Received March 13, 2009; revised and accepted July 28, 2009 